\title{
ACCIONES COLECTIVAS Y RECURSOS NATURALES EN CONFLICTO. HISTORIA AMBIENTAL DE LUCHAS URBANAS POR AGUA Y SIERRAS EN TANDIL, ARGENTINA.
}

\author{
Elsa Marcela Guerrero ${ }^{1}$ \\ Lucrecia Soledad Wagner ${ }^{2}$ \\ Corina Iris Rodríguez ${ }^{3}$ \\ Beatriz Soledad Sosa ${ }^{4}$
}

Recibido el 2 de diciembre de 2013, aprobado el 18 de febrero de 2015 y actualizado el 4 de mayo de 2015

DOI: 10.17151/luaz.2015.41.15

\section{RESUMEN}

En el municipio de Tandil, diferentes expresiones socioambientales han tenido lugar a nivel local en las últimas décadas. Algunas de estas acciones responden a los efectos ambientales de ciertas actividades -la minería, la instalación de actividades contaminantes, la lucha urbana por el acceso a la tierra, al agua y a mejores condiciones ambientales, la problemática de los residuos sólidos urbanos e industriales y otros reclamos de justicia ambiental-. El presente trabajo discute desde una perspectiva teórica y mediante el análisis empírico de ciertos casos, las principales consideraciones epistemológicas asociadas a conceptos centrales que permiten entender y explicar el accionar social frente a la lucha ambiental.

Por ello, interesa identificar ciertas problemáticas, describiendo los conflictos y las acciones colectivas de las luchas urbanas que reclaman mejoras en las condiciones ambientales a nivel local. El objetivo del presente trabajo es situar determinadas acciones colectivas en espacio y tiempo. Para ello se analizan cuatro casos de luchas urbanas suscitados por dos recursos naturales en pugna: el paisaje serrano y el recurso hídrico subterráneo.

La selección del estudio de caso como método de investigación responde al carácter exploratorio del tema abordado. La inferencia lógica inductiva favorece la identificación de las categorías de análisis más propicias para su abordaje y pone en evidencia formas de organización, estrategias colectivas, y respuestas frente a los reclamos.

Se emplean como técnicas de producción de conocimiento: la comparación, la observación documental -periódicos locales, sitios Web, archivos públicos y privados- y entrevistas a informantes calificados.

En todos los casos bajo análisis las luchas se enmarcan en un contexto de crisis del Estado como proveedor de espacios de participación que favorecen la legitimación de nuevos espacios para el reclamo socioambiental. En particular cada caso presenta singularidades y generalidades que son posibles identificar y describir. 


\title{
PALABRAS CLAVE
}

Minería, acceso al agua potable, luchas urbanas, historia ambiental, método comparativo.

\section{COLLECTIVE ACTIONS AND NATURAL RESOURCES IN CONFLICT. ENVIRONMENTAL HISTORY OF URBAN STRUGGLES FOR WATER AND HILLS IN TANDIL, ARGENTINA.}

\begin{abstract}
Different social-environmental expressions have occurred at the local level in the last decades in the Municipality of Tandil. Some of these actions respond to environmental effects of some activities -mining, contaminating activities installation, the urban struggles for access to land, water or better environmental conditions, the problems of urban and industrial solid waste and other environmental justice claims. This work discusses, from a theoretical approach and through the empirical analysis of certain cases, the main epistemological considerations associated to central concepts which allow to understand and explain social actions against the environmental struggle.
\end{abstract}

Therefore, it is interesting to identify certain problems describing the conflicts and collective actions of urban struggles claiming improvement in the local environmental conditions. The main goal of this work is to establish some collective actions in space and time. In order to do this, four case studies of urban struggle caused by two natural resources competing, the mountain landscape and undergraound water resources, are analyzed.

iCase study selection as research method responds to the exploratory nature of the topic addressed. Inductive logic inference favors the identification of the most appropriate category analysis for its approach and leave proof of organization forms, collective strategies and answers against the claims presented.

Comparison, documental observation -local newspapers, websites, private and public files- and interviews to qualified informants were used as knowledge production techniques.

In all the cases under study, struggles are framed by State crisis context as the provider of participation spaces that favor the legitimation of new spaces for the social-environmental claim. Particularly each case presents particularities and generalities that are possible to identify and describe.

\section{KEY WORDS}

Mining, access to drinking water, urban struggles, environmental history, comparative method. 


\section{INTRODUCCIÓN}

Gran parte de las problemáticas ambientales derivan en conflictos de carácter socioambiental que, a su vez, dan lugar a diversas clases de manifestaciones sociopolíticas u organizaciones con diferente grado de institucionalidad, variada metodología de participación y diversas relaciones de poder con el Estado.

Las acciones colectivas contemporáneas persiguen revertir las situaciones de inequidad, de derechos no reconocidos, de desequilibrios de poder que ponen de relieve las amenazas del proyecto productivista neoliberal global -cambio climático, inseguridad alimentaria, pobreza, crisis energética, enfermedades globales, agujero de ozono, lluvias ácidas, inseguridad nuclear, etc.- haciendo que los diversos intereses particulares de una comunidad se plasmen en el interés en la defensa de la propia humanidad y del planeta (Guerrero, 2013).

En ese sentido, el tema de los movimientos sociales de carácter ambiental está ocupando un lugar destacado en las ciencias sociales contemporáneas. Tradicionalmente, la investigación histórica-ambiental compartió la preocupación por las transformaciones antropogénicas de los ecosistemas a largo plazo. En los últimos años ha aumentado su interés por los aspectos políticos y distributivos del deterioro ambiental, los efectos de la "acumulación" y del "intercambio desigual", que permiten expresar una figura más completa y compleja de la dinámica socio-ecológica.

Desde otras especializaciones de las ciencias sociales antropología ecológica, sociología ambiental, ecología política, economía ecológica, entre otras- también se aborda el tema de la organización social frente a la crisis ambiental contemporánea. Y se aportan y revisan teorías para explicar las relaciones sociedad-naturaleza. En tal sentido, es posible identificar procesos de transdisciplinariedad y enriquecimiento teórico de conceptos entre diferentes ciencias y métodos que podrían favorecer el entendimiento del tema de las movilizaciones socioambientales. No obstante, es necesario reconocer la naturaleza incipiente y la falta de consenso entre los diferentes enfoques, lo que entorpece las posibilidades teóricas para explicar e interpretar satisfactoriamente estas problemáticas sociales (Guerrero, 2013).

En Tandil, Argentina, pueden identificarse diferentes procesos de participación socioambiental en las últimas décadas que merecen ser abordadas como casos locales de reclamos por justicia ambiental frente al avance del desarrollo, la urbanización y el deterioro de los recursos naturales. En este trabajo se comparan cuatro estudios de caso asociados a la pugna por el uso/acceso a determinados recursos naturales, fundamentalmente: el agua y el paisaje serrano.

Las condiciones de emplazamiento de la ciudad y los procesos histórico-económicos del desarrollo urbano local son el contexto 
espaciotemporal que enmarca los casos seleccionados. La ciudad se emplaza en un valle rodeado por sierras que favorecieron la actividad minera -hoy son reconocidos como recurso turístico y paisajístico a conservar, por un lado-, y que limitan el acceso al agua en determinados sectores de reciente urbanización, por otro.

\section{METODOLOGÍA}

Para abordar la evidencia empírica sobre estos casos, se analizan las principales diferencias conceptuales y epistemológicas entre las nociones -conflictos, acción colectiva, movimientos sociales, movilizaciones y protestas- que fueron enmarcadas en el título anterior. Esto resulta de utilidad para el abordaje de la problemática ambiental y de las agencias sociales que se generan a partir de la disputa por bienes naturales.

Luego se caracterizan y comparan en términos operacionales estos conceptos en los estudios de caso seleccionados para Tandil, con el objetivo de situar la ocurrencia de los mismos en el tiempo y espacio, describiendo aspectos generales de cada uno.

Para el análisis de los casos se han empleado técnicas en investigación social que permitieron la descripción y sistematización de la información referida a los casos locales. Se ha realizado la observación documental de fuentes secundarias disponibles en archivos, sitios Web y la prensa escrita y oral locales. Esto permitió sistematizar los eventos a través de un anclaje temporo-espacial, identificar actores, acciones y estrategias en cada caso. También se produjo información primaria a partir de la entrevista a informantes calificados y referentes locales asociados a los casos bajo estudio.

Una vez obtenida esa información se procedió a la comparación de los casos de acuerdo a atributos o aspectos que identifican las acciones colectivas a nivel local. Siguiendo a Sartori y Morlino (1994, p. 35): "las comparaciones que sensatamente interesan se llevan a cabo entre entidades que poseen atributos en parte compartidos (similares) y en parte no compartidos (y declarados no comparables)". La comparación remite a la clasificación... Clasificar es ordenar un universo en clases que son mutuamente excluyentes, por lo tanto clasificar es establecer similitudes y diferencias. Se entiende, no obstante, que "igual" es una noción relativa. Lo esencial, es que la pregunta "que es comparable" sea formulada así: comparable ¿en qué aspecto? Con respecto a la comparación de casos, el caso se elige expresamente o porque resulta útil para generar hipótesis, o porque es crucial a la hora de confirmar o no una teoría. Cuando es así el análisis de casos y el análisis comparativo son complementarios. Pero queda también claro que los estudios de caso seleccionados deben ser implícitamente comparativos o comparables (Sartori y Morlino, 1994). 


\section{DISCUSION Y ANALISIS DE RESULTADOS}

\section{Repensando los conflictos ambientales como parte de la historia ambiental local}

Abordar las acciones colectivas vinculadas a problemáticas ambientales en Tandil, responde a la necesidad de dotarlas de la especificidad que les otorga el lugar en el cual estos procesos emergen, y que configura los conflictos que pueden propiciar este accionar social.

En el análisis de los conflictos ambientales, es
escaso el desarrollo de investigaciones
focalizadas en las formas y maneras particulares
que implementan las distintas sociedades y
culturas en su relación con la naturaleza y de las
cuales devienen, precisamente, los conflictos
ambientales. (Galafassi y Zarrilli, 2002, pp. 7-8)

Ahondar en la particularidad del lugar, nos permite hacer foco en la especificidad de las relaciones de poder local. Los lugares son creaciones históricas, que deben ser explicados, no asumidos, y esta explicación debe tomar en cuenta las maneras en las que la circulación global del capital, el conocimiento y los medios configuran la experiencia de la localidad (Escobar, 2011).

Este trabajo se enmarca en un contexto de creciente conflictividad socioambiental y de producción científicoacadémica sobre los mismos. En Argentina se han generado, sobre todo en la última década, diversos conflictos socioambientales -o que consideramos que pueden ser abordados como tales-. Hacemos esta diferenciación porque, como señala Martínez (2004), han existido y existen conflictos y movimientos socioambientales que no fueron identificados o que no se autodenominan como tales. "los actores de tales conflictos muchas veces no utilizan un lenguaje ambiental, y esta es una de las razones por la cual esta tercera corriente del ecologismo [el ecologismo popular] no se identificó hasta los años ochenta" (Martínez, 2004, p. 31)..$^{5}$ Actualmente, podemos afirmar que asistimos a una ambientalización de las luchas sociales, que puede designar tanto el proceso de adopción de un discurso ambiental genérico por parte de los diferentes grupos sociales, como la incorporación concreta de justificativas ambientales para legitimar prácticas institucionales, políticas, científicas, entre otras. En concordancia con ello, consideramos que profundizar el conocimiento sobre los conflictos y movilizaciones locales posibilita la caracterización de procesos de ambientalización específicos a determinados lugares, contextos y momentos históricos, en los que nuevos fenómenos van siendo construidos y expuestos a la esfera pública, o viejos fenómenos son renombrados como "ambientales" (Acselrad, 2010).

En cuanto a las definiciones conceptuales, "Hay acuerdo sobre el hecho de que el conflicto es una forma de interacción entre individuos, grupos, organizaciones y colectividades que implican enfrentamientos por el acceso a recursos escasos y su 
distribución" (Bobbio, Mateucci y Pasquino, 1991, p. 298). Para estos autores, los recursos escasos se presentan bajo formas de poder, riqueza y prestigio. Incluyen en esta noción al territorio, y destacan que algunos recursos pueden desearse como fines en sí mismos, mientras que otros pueden servir para mejorar las posiciones en vista de nuevos y probables conflictos.

Henri Acselrad menciona el carácter indisociable del complejo formado por el par sociedad-medio ambiente, que justifica el entendimiento de que las sociedades se reproducen por procesos socio-ecológicos. Así, en el proceso de su reproducción, las sociedades se confrontan a diferentes proyectos de uso y significación de sus recursos ambientales. Es decir, que el uso de estos recursos está sujeto a conflictos entre distintos proyectos, sentidos y fines. Vista desde esta perspectiva, la cuestión ambiental es intrínsecamente conflictiva (Acselrad, 2004).

Por otra parte, la acción colectiva (AC) nos remite a un fenómeno más abarcativo que, por ejemplo, el de movimiento social (MS): indica un actor social colectivo, que presenta menores garantías respecto a su continuidad, su nivel de integración interna, su estructura y organización, la construcción de una identidad, y la planificación de tácticas y estrategias. "El término conducta o acción colectiva es excesivamente amplio [...], únicamente excluye, en un extremo, los comportamientos de agregado y, en el otro, las acciones individuales" (Ramírez, 1991, p. 95). Esta denominación permite entonces dar cuenta de una amplia gama del accionar colectivo de diversos grupos de la población de Tandil, que luego se procederá a clasificar con base en otros conceptos más específicos: movimiento social, protesta y movilización.

El concepto de movimiento social (MS) comparte con el de AC ciertas características, como la identificación de un actor social y la existencia de valores compartidos. Sin embargo, la continuidad en el tiempo, los grados de organización, el desarrollo de tácticas y estrategias de lucha, la conformación de una identidad colectiva, la amplia visión de los problemas, solidaridades fuertes y la interacción con el proceso histórico de la sociedad de la cual forman parte, son algunas de las características más relacionadas con la noción de MS. La propia definición nos lleva a pensar el movimiento social como fundante de vínculos sociales y potenciador de la conformación de una identidad colectiva. ${ }^{6}$ Sobre el concepto de identidad, "en la intersección entre prácticas y discursos que interpelan a los sujetos (señalando una particular locación social de pertenencia y a la vez marcando al otro) y los procesos que producen subjetividades, se encuentra la identidad" (Saldi, 2011, p. 42). Es decir, que la identidad marca que un colectivo se enfrente a otro, y el ordenamiento del mundo como parte primordial de la identidad también se refiere a la naturaleza que rodea a los seres humanos y con ello a las relaciones que entablan con la misma. En conclusión, las categorías que definen a las identidades no están definidas a priori sino que su dinamismo deviene de construcciones históricas discursivas en contextos de relaciones de poder. 
Es decir, que la noción MS hace referencia a un cambio de comportamiento llevado a cabo por personas que poseen afinidad de intereses y valores, y se movilizan en común para lograr ciertos objetivos $u$ oponerse a ciertos cambios que los afectan directa o indirectamente. Son fenómenos sociopolíticos que surgen ante la falta de respuesta de las instituciones existentes, o del cuestionamiento al modelo de desarrollo y/o participación dominante, interviniendo en el proceso de transformación social, promoviendo cambios u oponiéndose a ellos, mediante formas de acción institucionales y no institucionales, por las que intentan movilizar círculos más amplios de la sociedad. Asimismo, poseen formas de acción y organización variables, una composición social heterogénea y formas de participación múltiples y cambiantes. Están basados en condiciones sociales e históricas específicas, y mantienen una continuidad que los diferencia de otros fenómenos sociales (como la protesta social).

Siguiendo a Da Gloria Gohn (2006), afirmamos que los movimientos sociales son expresiones de poder de la sociedad civil, y su existencia, independientemente del tipo de sus demandas, siempre se desenvuelve en un contexto de correlación de fuerzas social, conformando, por lo tanto, procesos políticos. Puntualizando así en el conflicto social y político (y dejando de lado el conflicto del individuo en el nivel psicológico), podemos establecer así que los movimientos sociales están implícitamente vinculados a la existencia de un conflicto, pero es importante diferenciarlos, ya que no todos los conflictos potencian la emergencia de movimientos sociales $\mathrm{y} / \mathrm{o}$ acciones colectivas.

La continuidad del movimiento es para muchos autores una característica que establece diferencias entre los movimientos sociales y otras formas de acción colectiva. Entre ellos, fenómenos como la protesta social espontánea, representan procesos mucho menos estructurados, que no poseen ni su duración ni las estructuras comunicativas bastante elaboradas de los movimientos (Riechmann y Fernández, 1994). Sin embargo, se discute que para arribar a una protesta, al "momento visible" para el resto de la sociedad, previamente se fue gestando un proceso que, sin ser evidente, hizo posible que el conflicto desembocara en una protesta social. Es decir, puede haber acción colectiva más allá y previamente a su materialización a simple vista (Scribano, 2005). Federico Schuster también hace referencia al proceso previo a la protesta, ya que, si bien afirma que puede existir el caso en que la acción constituya una auténtica novedad -que no ha surgido de ningún movimiento conocido ni reconoce antecedente alguno en acciones anteriores de sus miembros-, destaca que es muy raro encontrar esta categoría de protesta en su forma pura, ya que siempre hay alguna clase de interacción social antes de una acción de protesta (Schuster, 2005).

Por su parte, el término movilizaciones viene utilizándose en los últimos años para denominar a procesos menos organizados que un MS, pero que contienen algunos de sus elementos y poseen 
perspectiva de conformar un movimiento, lo que lo diferencia de las acciones de protesta (Wagner, 2011).

\section{Acciones colectivas y una aproximación a la historia ambiental local}

A continuación se describen las principales características de los casos seleccionados a nivel local. Además, se comparan los casos elegidos de acuerdo a los siguientes criterios o aspectos: actores implicados, grados de organización y estrategias de acción desarrolladas, conformación de una identidad colectiva, conflictos y valores ambientales en juego, rol del Estado en el conflicto y, a partir de ello, su clasificación como protesta, movilizaciones y/o movimientos sociales. Cabe destacar que se pretende caracterizar procesos que presentan continuidad temporal.

La Figura 1 sitúa ambos conflictos espacialmente.

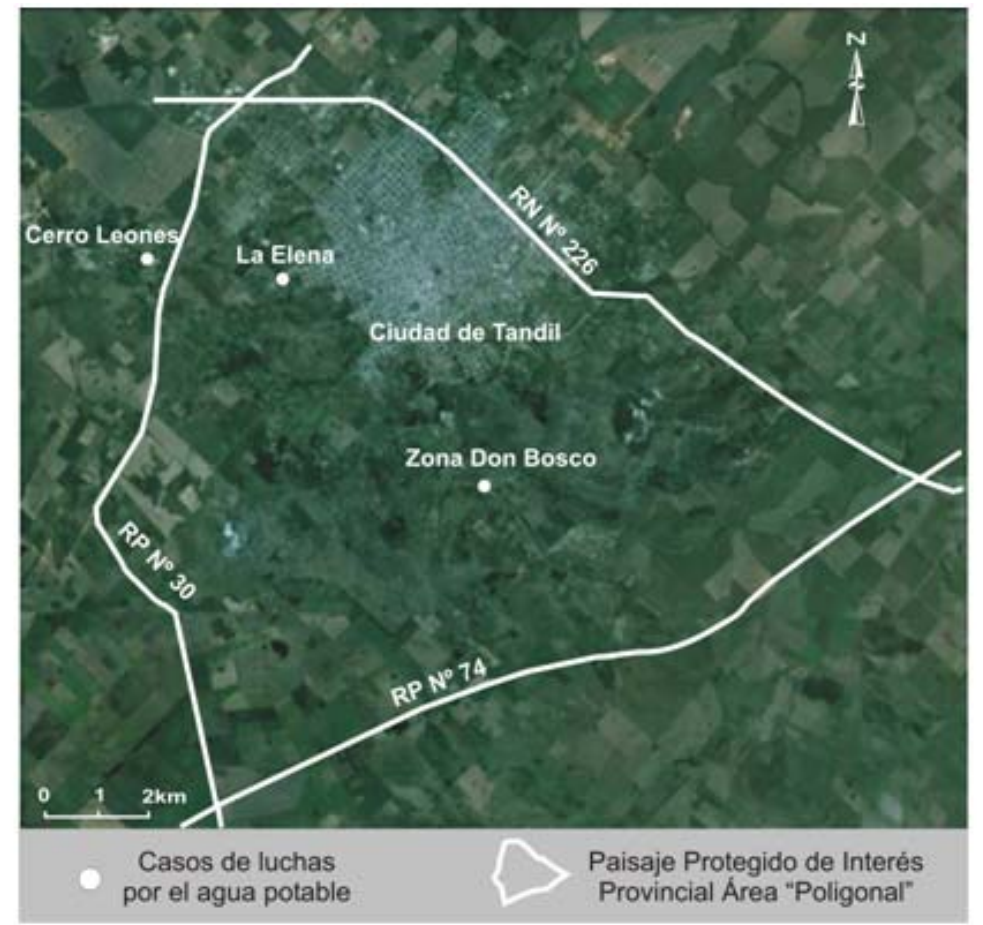

Fuente: Elaboración propia con base en Google Maps.

Figura 1. Localización de los casos de lucha por el agua y de la poligonal declarada paisaje protegido.

\section{Luchas urbanas por acceso al agua en tres casos: "Cerro Leones", "La Elena" y zona Don Bosco}

Se analizan tres casos en los que se destaca el agua subterránea como único recurso para el abastecimiento humano (Figura 1). Primero se describe brevemente cada caso en particular para comprender la cronología de cada uno. 
Por las características hidrogeológicas del sistema serrano de Tandilia, en los tres casos se presentan dificultades para la extracción del recurso subterráneo. Simultáneamente, tampoco se cuenta con sistemas de recolección y tratamiento cloacal, generando una carga contaminante en el medio subterráneo y afectando la calidad del agua tanto en sus características químicas como microbiológicas (Rodríguez, 2010; Rodríguez et al., 2013).

El barrio Cerro Leones se encuentra ubicado al SO de la ciudad, a una distancia de $6 \mathrm{~km}$, y surgió asociado a la minería en el siglo pasado. Cuenta con aproximadamente 500 habitantes y se encuentra en crecimiento. Frente a las reiteradas protestas de los vecinos del barrio, en 2007 comenzaron los reclamos ante el Ente Nacional de Obras Hídricas de Saneamiento (ENOHSA) para gestionar la obra de acceso al agua potable (Rodríguez et al., 2010). Los problemas de calidad del agua, sumados al descenso de niveles debidos a la sequía de 2008, impulsaron la movilización de los vecinos conformando una comisión barrial.

En 2009, los reclamos locales fueron escuchados a nivel nacional y, en ese marco, ENOHSA presentó el proyecto Proarsa (Programa de Asistencia en Áreas con Riesgo Sanitario), tanto para "Cerro Leones" como para "La Elena". En abril del mismo año se licitó la obra de "Cerro Leones", difundida en el diario La Nación, que fue adjudicada a la empresa Ecosur Bahía por un monto de más de 2,4 millones de pesos. Finalmente, la ejecución quedó suspendida.

En febrero de 2010 y tras los reclamos de los vecinos se reactivó la obra y se ejecutó en solo 3 meses, brindando la posibilidad de conexión a unas 80 familias. Además, se prevé en un futuro cercano la construcción en el Parque Industrial Hermanos Bariffi de un nuevo pozo que permitirá sumar mayor caudal a los dos pozos que se encuentran ubicados en la misma área geográfica y bombean agua al tanque cisterna del barrio La Movediza, ubicado a 2,5 kilómetros de "Cerro Leones".

En el caso del paraje "La Elena", se trata de una urbanización relativamente reciente donde se ha densificado la construcción de residencias permanentes y temporales en los últimos 20 años, a partir del loteo de lo que fuera una estancia denominada justamente La Elena. Este sector se caracteriza por la belleza del paisaje y las vistas hacia la ciudad que lo dotan de condiciones estéticas excepcionales. No obstante, está sujeto a los problemas de accesibilidad al agua potable por ubicarse en zona de piedemonte y con presencia de roca granítica en superficie en muchos sectores del sistema serrano (Guerrero, 2011).

En enero de 2010, un importante grupo de vecinos participó de una reunión tendiente a formar la comisión barrial que en forma inmediata comenzó a plantear ante las autoridades municipales sus múltiples requerimientos, entre los que se destaca la provisión de agua a un creciente número de viviendas (Radio LU22, 2010). En el barrio "las necesidades son muchas y van surgiendo por sectores, pero en lo que estamos todos unidos es 
en el pedido por el agua, porque las napas se están secando por todos lados. Es una zona con mucha piedra", señalaron inicialmente el presidente de la comisión, y la pro tesorera.

Los referentes de la barriada explicaron que:

[...] hace cinco años que presentamos el pedido y nos habían informado que la obra se iba a hacer junto con la de Cerro Leones, que se había pedido a Nación. Pero ahora salió la de Cerro Leones y la nuestra no, por lo que los vecinos estamos preocupados. [...] estamos enojados porque no hay agua, que es fundamental. Se puede estar sin gas o cloacas, pero el agua es necesaria [...] el problema es que se está agrandando tanto la capacidad habitacional en la zona que los pozos se secan y no dan abasto.

De allí que "quienes no hicieron el pozo hace unos años, ahora no pueden, ya que es todo piedra y hay que bajar más de 30 metros para tener agua" (Radio LU22 28/01/2010).

Actualmente, quienes no poseen un pozo con abastecimiento suficiente están:

[...] a expensas de que vaya el camión de agua, que carga en Del Valle y Fragata Sarmiento. Cuando uno circula ve que pierde un tercio de la carga por inconvenientes tales como mangueras rotas en el kilómetro que dista con el barrio. (Radio LU22, 28/01/2010)

Los vecinos también aclararon que:

[...] el camión va una vez por semana. Si es feriado o llueve, hay que esperar para que pueda entrar y dejar el agua. Además, hay que estar y tener abierto, ya que de lo contrario hay que esperar a la próxima semana. (Radio LU22, 28/01/2010)

Si bien éste fue el eje principal de la reunión, no todos los reclamos apuntaban a las autoridades, sino que también se solicitó a la población en general que no arroje sus residuos en el barrio, debido a que los vecinos encuentras bolsas con restos de distinto origen, principalmente luego de los fines de semana. Esta situación se ve agravada por la escasa cobertura de recolección municipal de residuos en la zona.

Durante 2012, la comisión vecinal no cesó sus reclamos, participando incluso de la Banca XXI del Concejo Deliberante de Tandil. En noviembre de 2012, un diputado provincial presentó un recurso de amparo ante la justicia nacional solicitando la realización de la obra de red de agua para el paraje "La Elena". 
En diciembre del mismo año, un Juez Federal en lo Contencioso Administrativo indicó en su resolución que:

[...] la Dirección de Obras Sanitarias de Tandil, el Municipio de Tandil y el ENOHSA, dentro del marco de sus respectivas competencias y a la mayor brevedad posible, deberán arbitrar los medios necesarios a fin de que los vecinos del barrio La Elena tengan acceso a la red de agua potable, salubre y aceptable, para uso personal y doméstico. (Radio LU22, 28/12/2012)

Si bien el conflicto de "La Elena" es mucho más reciente y aún requiere tiempo y estrategias de movilización y protesta para su resolución, no obstante, es importante adelantar el caso como evidencia de un proceso al que no escapan otras áreas de expansión urbana sobre el pie de sierras a futuro (Guerrero, 2012).

Con una situación similar se encuentra la zona Don Bosco emplazada al sur de la ciudad, donde en los últimos 10 años se ha dado un proceso de urbanización asociada a emprendimientos turísticos, especialmente complejos de cabañas. Como en los otros casos, la geología condiciona la extracción de agua en cantidad suficiente y se suman problemas de calidad por la ausencia de servicios sanitarios básicos (Rodríguez et al., 2013). En ese sentido, existen evidencias de dificultades de acceso al agua, secado de pozos, y la necesidad de profundizar las perforaciones, comprar agua para llenar piletas, y problemas de calidad bacteriológica y química. No obstante, el grado de organización de los vecinos es débil y con poco grado de organización. Algunos habitantes de la zona se han agrupado en la organización "Vecinos por un desarrollo sustentable", que reclama lo regulado en el Plan de Desarrollo Territorial de $2005^{7}$ y que afecta el uso potencial de sus tierras con fines inmobiliarios. Entre otros reclamos piden obras para el abastecimiento de agua en la zona (Radio LU22, agosto de 2011).

A continuación se analizan en forma conjunta los tres casos de conflictos por el acceso al agua en la localidad de Tandil. Se emplean las siguientes categorías de análisis que permiten la comparación entre sí y con el caso de la minería a cielo abierto:

- Actores implicados: en los tres casos son numerosos los actores e intereses implicados, incluyendo a los vecinos, las comisiones barriales, ONG, Municipio de Tandil, Obras Sanitarias Tandil, ENOHSA, empresas de agua envasada, perforistas, personas vinculadas a actividades turísticas, legisladores provinciales, Estado nacional. Los medios contribuyen a crear la imagen pública del conflicto.

- Grados de organización y estrategias de acción: los habitantes de estos barrios entran en 
conflicto quejándose ante las autoridades municipales y provinciales por la falta de servicios, así como también realizan reclamos puntuales al resto de la población.

Existen diferentes situaciones según el caso, desde vecinos que realizan los reclamos mediante organizaciones ya existentes hasta nuevos grupos creados a partir de preocupaciones de carácter explícitamente ambiental (como "Vecinos por un desarrollo sustentable").

Los vecinos de "Cerro Leones" iniciaron su movilización en 2007 para gestionar la obra para el aprovisionamiento de agua de red. Asimismo, en enero de 2010 un grupo de vecinos de "La Elena" conformaron la comisión barrial que plantea ante las autoridades municipales sus múltiples requerimientos, entre los que se destaca la provisión de agua a un creciente número de viviendas. Un conjunto de vecinos de la avenida Don Bosco integran una agrupación que reclama por el uso del territorio, en relación a lo estipulado por el Plan de Manejo Ambiental. Se pone de manifiesto que desde hace unos años la comunidad ha generado diferentes estrategias de organización social tendientes a acceder al sistema de agua de red.

- Identidad colectiva: no se reconocen hasta el momento en el devenir del conflicto elementos que permitan plantear la existencia de una identidad colectiva nacida a partir del mismo, pero sí la consolidación de solidaridades fuertes entre los vecinos para solucionar los problemas barriales.

- Conflictos y valores ambientales en juego: la existencia de antecedentes de contaminación del agua subterránea sumada a las dificultades para su extracción, a los intensos bombeos y secado de perforaciones en algunos sectores y a la ausencia de servicios sanitarios básicos, dan lugar a reclamos y conflictos por un recurso tan vital como el agua.

- Rol del Estado: en "Cerro Leones" el Estado llevó adelante la obra de abastecimiento de agua potable a principios de 2010, dando una respuesta concreta al reclamo. "La Elena" en diciembre de 2012 obtuvo un amparo judicial por el cual los organismos competentes en materia hídrica deben llevar a cabo la obra de provisión de agua para el sector. Por lo cual el conflicto en este paraje se encuentra pendiente de 
resolución, pero más avanzado que en el caso de Don Bosco, donde está en una etapa inicial.

\begin{abstract}
- Clasificación como Protesta / Movilizaciones I Movimientos sociales: en el caso de "Cerro Leones" se identifican acciones de protesta que desembocaron en movilizaciones y en la utilización de una organización barrial ya existente. El surgimiento de otros problemas en los que esta organización se implique permitirá identificar si se trata de un movimiento social en consolidación. En el caso de "La Elena" se ha conformado una organización barrial que está llevando adelante acciones de protesta, y en Don Bosco se ha creado una organización pero aún no ha habido movilización social con respecto a la problemática hídrica.
\end{abstract}

Luchas por la preservación de las sierras ante la minería a cielo abierto y el avance de la urbanización: un recurso y dos frentes de lucha

Al igual que en el caso del agua, primero se describe brevemente el conflicto y luego se analiza con las mismas categorías que el recurso agua.

El inicio del conflicto entre la conservación del paisaje serrano y determinados usos de este espacio, como la actividad minera, es centenario. El proceso de minería sobre las sierras permaneció "invisible" durante muchos años -se asocia a las primeras actividades desarrolladas en el partido-. La actividad proveyó de adoquines y piedras de aplicación a nivel local y nacional a principios del siglo $\mathrm{XX}$, luego se dedicó a la extracción de rocas de aplicación principalmente.

Un punto de inflexión que puede citarse fue la audiencia que terminó con la firma del Acuerdo Marco en 1999/2000. En el mismo se acordaba un cese paulatino de la actividad canteril en el sector denominado "la poligonal", cumpliendo, de algún modo, lo que establecía la legislación municipal sobre el desarrollo de la actividad fuera de un área poligonal entre las Rutas Provinciales № 30 y 74 y la Ruta Nacional № 226 (Figura 1), previendo el futuro desarrollo urbano en esa área. No obstante, los puntos acordados por los empresarios de la actividad en el Convenio no se cumplieron, lo que dio impulso a estrategias permanentes y de diferente naturaleza por parte de la Multisectorial y la posterior Asamblea Ciudadana por la Preservación de las Sierras.

En relación a lo anterior, es importante destacar que, desde 1999, un grupo de vecinos y vecinas, preocupados por el impacto que generaban las canteras en las sierras de la ciudad, conformaron la Multisectorial por la Preservación de las Sierras, a la que decidieron darle carácter de organización no gubernamental. Los impulsaba, como objetivo central, la preservación del ecosistema serrano de forma integral. Luego de llevar a cabo diversas acciones, en 2006 deciden realizar una 
amplia convocatoria a toda la comunidad de Tandil con el fin de realizar una marcha y posterior asamblea, en la cual debatir y proponer soluciones a la problemática de las sierras (Hesse, 2012). Ya en el año anterior, 2005, la Multisectorial había presentado una propuesta de Ordenanza de Áreas Protegidas y Consulta Popular ante el Honorable Concejo Deliberante local, haciendo uso de la Banca XXI (Multisectorial por la Preservación de las Sierras de Tandil y Asamblea Ciudadana en Defensa de las Sierras, 2011).

Con la continuidad de las marchas y las asambleas, surge la Asamblea Ciudadana por la Preservación de las Sierras de Tandil. Sostiene el mismo objetivo central que la Multisectorial preservar el ecosistema serrano de forma integral- pero desde otro lugar, con la incorporación de un gran número de personas y tomando la movilización y la asamblea como modalidad de acción. Es decir, los integrantes de la Asamblea eran aquellas personas de la Multisectorial que veían la necesidad de crear un nuevo espacio de lucha, quienes encontraron en el formato asambleario la forma de organización democrática que permite la participación absoluta de los integrantes. Este grupo de personas luego de la convocatoria mencionada se amplió, incorporando un gran número de ciudadanos -en su mayoría jóvenes- quienes brindaron su energía a la causa, que se vio así renovada (Hesse, 2012).

Una de las actividades más destacadas fue la realización, en septiembre de 2009, de una Consulta Popular Comunitaria, en la que, durante una semana, alrededor de 400 voluntarios recorrieron las calles de la ciudad de Tandil, y de las localidades de Vela y Gardey, golpeando "puerta por puerta" preguntando acerca de la propuesta de la Asamblea sobre declarar Áreas protegidas a las sierras de Tandil. Los resultados de la consulta fueron publicados el $1^{\circ}$ de octubre, y demostraron que, siendo la cantidad de votos totales $14.268,14.135$ se manifestaron de acuerdo a:

Solicitar a la Legislatura y a todas las autoridades responsables que las sierras de Tandil sean declaradas áreas protegidas, para impedir por ley y sin excepciones los usos nocivos como las canteras, construcciones y forestaciones exóticas sobre las sierras. Solicitamos la protección del conjunto serrano por su inconmensurable valor ambiental y como cuenca hídrica. El cese de la destrucción debe ser inmediato, garantizando los ingresos laborales de los trabajadores actuales de las mineras y la reconversión de las mismas hacia actividades compatibles con las áreas protegidas.

Solicitud que cada una de las 14.000 personas firmó para ser presentada a las autoridades (Hesse, 2012). 
Luego de cinco años de lucha sin interrupciones y cada vez más efectivas, en 2010 se sancionó la Ley de Paisaje Protegido No 14.126, la cual "[...] tiene por objeto conservar y preservar la integridad del paisaje geográfico, geomorfológico, turístico y urbanístico del área especificada en el artículo $1^{\circ}$, la denominada poligonal" (Artículo $2^{\circ}$ ). Esta ley junto con el Plan de Desarrollo Territorial (PDT) aprobado en 2005, se constituyen en herramientas legales relevantes para llevar adelante la protección del sistema serrano. A modo de resumen la Ley declara "Paisaje Protegido de Interés Provincial" el área del Partido de Tandil denominada "la poligonal" (Figura 1), prohibiendo la actividad minera de las canteras que allí se localizan. Por su parte, el PDT rige la planificación y gestión urbana y rural del territorio del municipio de Tandil, establece los principios y las estrategias de actuación territorial, los programas y proyectos de acción, regula el uso, ocupación, subdivisión y equipamiento del suelo y determina el sistema de gestión territorial. Sin embargo, existen contradicciones entre la ley provincial y el PDT municipal, obstaculizando la preservación de las sierras, y al mismo tiempo, posibilitando que se realicen excepciones a particulares respecto al cumplimiento de determinados aspectos de las políticas públicas mencionadas (Girado, 2011). Entre las inconsistencias entre el PDT y la Nueva Ley pueden señalarse los usos establecidos por el plan y los de la nueva Ley; la existencia de una "cota" o altura máxima permitida para la urbanización que "posibilitaría" el uso residencial en el área protegida como las más importantes.

Por su parte, los empresarios mineros y los propietarios de los terrenos ubicados sobre las sierras manifestaron sus quejas al Estado respecto a la vigencia de las mencionadas medidas legales, argumentando que las regulaciones sobre el uso del territorio y los recursos "lesionan derechos básicos" como es el derecho a la propiedad privada. Detrás de este discurso existen intereses económicos para lo cual se le solicita al Estado poder utilizar las parcelas y subdividirlas con el objetivo de realizar emprendimientos turísticos, obtener un mayor número de lotes y hacer un negocio inmobiliario más rentable. El decreto de reglamentación de la Ley № 14.126 establece los lineamientos específicos para la formulación del Plan de Manejo Ambiental que permitirá la conservación de las sierras, por un lado, y la posibilidad del desarrollo de ciertas actividades compatibles con ese objetivo.

Como se desprende de lo antes destacado, la disputa en torno a los derechos de propiedad vincula intrínsecamente el conflicto por la preservación de las sierras ante la actividad minera con el del avance de la urbanización sobre estos espacios serranos. Este avance es un proceso reciente que data de los años ochenta y se ha incentivado en la última década, cuando los recursos sierras y suelo urbano en el paisaje serrano aumentan su valor para el mercado inmobiliario, dando lugar a diferentes actividades especulativas -inmobiliarias, turísticas-, que intentan aprovechar económicamente las condiciones naturales de estos espacios. Algunos vestigios de conflictos se asocian al debate y la implementación del Plan Desarrollo Territorial vigente entre 2003 y 2005 que regula la urbanización y sus características a 
nivel local, a lo que se suma el ya descrito conflicto reciente asociado a la Ley de Paisaje Protegido, que afecta los intereses de los propietarios que quedan dentro de la zonificación exigida por la ley.

Esta ley tampoco ha conformado a la Asamblea y la Multisectorial, para las cuales la problemática continúa y "la Ley de Paisaje Protegido, si bien resulta ser un paso, es sólo eso, apenas un paso. Pero no se puede hablar de esta Ley como la solución a un conflicto tan complejo" (Multisectorial por la Preservación de las Sierras de Tandil y Asamblea Ciudadana en Defensa de las Sierras, 2011, p. 573). Como ya fue destacado, la Multisectorial y la Asamblea postularon desde los inicios un proyecto que declarara la protección de todo el cordón serrano del partido de Tandil como Áreas Protegidas.

De acuerdo a las categorías empleadas, el conflicto puede describirse en términos de:

- Actores implicados: la invisibilidad de la problemática que generó la actividad minera sobre las sierras se asocia a la lógica de mercado imperante sobre el uso colectivo del recurso serrano. Esta cuestión ambiental a nivel local generó fuertes enfrentamientos entre la sociedad civil y sus organizaciones multisectorial y asamblea-, los empresarios privados de la actividad minera, los propietarios de los terrenos localizados sobre las sierras y el Estado.

- Grados de organización y estrategias de acción: el reclamo de la sociedad civil por la preservación de las sierras dio lugar a la formación de dos organizaciones: la Multisectorial y la Asamblea Ciudadana por la Preservación de las Sierras, quienes reclaman una efectiva e integral conservación de las sierras a partir de su declaración como Áreas Protegidas. Otro actor es el Estado, foco de sus exigencias: que intervenga en la gestión del recurso a los fines de lograr su acceso público y gratuito, y que consiga el cese de la actividad minera y de las construcciones sobre el faldeo serrano. Por otra parte, los empresarios mineros y los agentes inmobiliarios también reclaman al Estado la afectación de sus derechos de propiedad. Otro actor implicado son los trabajadores mineros, cuyo destino laboral está en juego en este conflicto. La Multisectorial ha llevado adelante numerosas solicitudes ante las autoridades municipales y provinciales, como así también ante otros organismos. Además de tareas de educación y difusión del tema, las movilizaciones dieron origen a la Asamblea Ciudadana en Defensa de las Sierras de Tandil. 
En 2009 esta Asamblea llevó adelante una inédita Consulta Popular Comunitaria. Sumado a los reclamos de ambas organizaciones, como ya se destacó, se contrapone el reclamo de los empresarios mineros y los propietarios de los terrenos (con intereses especulativos con fines mobiliarios y turísticos) ubicados sobre las sierras.

- Identidad colectiva: si bien no toda la sociedad tandilense forma parte de las organizaciones identificadas en este conflicto, el apoyo social, manifestado en la capacidad de presión en la toma de decisiones, permiten identificar la conformación de una identidad colectiva asociada al entorno ambiental que se desea preservar. El símbolo de apoyo a la preservación de las sierras -una cinta verde que los tandilenses colocaban en casas y automóviles- tuvo una fuerte visibilidad en los momentos más álgidos del conflicto.

- Conflictos y valores ambientales en juego: los intereses de empresarios mineros, de los agentes inmobiliarios y turísticos entran en conflicto con la valoración por parte de otros sectores de la población (como la Multisectorial y la Asamblea) de las sierras como un bien colectivo y público (Ulberich, Miranda del Fresno y Morrone, 2012), bajo el argumento de que las sierras son un recurso no renovable cuyo valor trasciende lo monetario y que habrá de ser puesto a resguardo como legado para futuras generaciones de tandilenses (Girado, 2011). Cuando a fines de la década del noventa algunos vecinos de Tandil se organizan para solicitar la preservación de todo el sistema serrano, introducen a la discusión sobre los usos de las sierras otros valores ecosistémicos, históricos y culturales que estas poseen. Paralelamente, el crecimiento de Tandil como destino turístico potenció los intereses económicos que el sector inmobiliario tenía sobre los espacios serranos.

Además, existe una incompatibilidad de usos entre el avance de la urbanización y la actividad minera en áreas hoy encuadradas en la normativa vigente de ordenación y la creación de un área de paisaje protegido.

- Rol del Estado: el Estado impulsó la Ley de Paisaje Protegido № 14.126, que no cumple con las expectativas de las organizaciones que luchan por preservar las sierras, ya que se protege solo una parte de las mismas. Aún se 
está implementando la reglamentación sobre usos en el área protegida. Quedan pendientes otros temas, como la incompatibilidad entre el Plan de Ordenamiento Territorial y la Ley de Paisaje Protegido, y la reinserción de los trabajadores mineros afectados.

\section{- Clasificación como Protesta / Movilizaciones I Movimientos sociales: la trascendencia social que ha tenido el conflicto y la permanencia en el tiempo y legitimidad social del accionar de la Multisectorial y Asamblea permiten identificar la existencia de un movimiento social en relación a la preservación de las sierras. Por otra parte, el accionar de estas organizaciones ha intervenido en el proceso histórico reciente de la sociedad de la cual forman parte, dando lugar a usos públicos de espacios históricamente invisibilizados y apropiados para actividades privadas.}

La Figura 2 simplifica en forma esquemática las luchas y los procesos de organización colectiva a nivel local. Describe las disputas de intereses y valores en juego y sintetiza en forma de imbricaciones conceptuales las principales teorizaciones discutidas precedentemente.

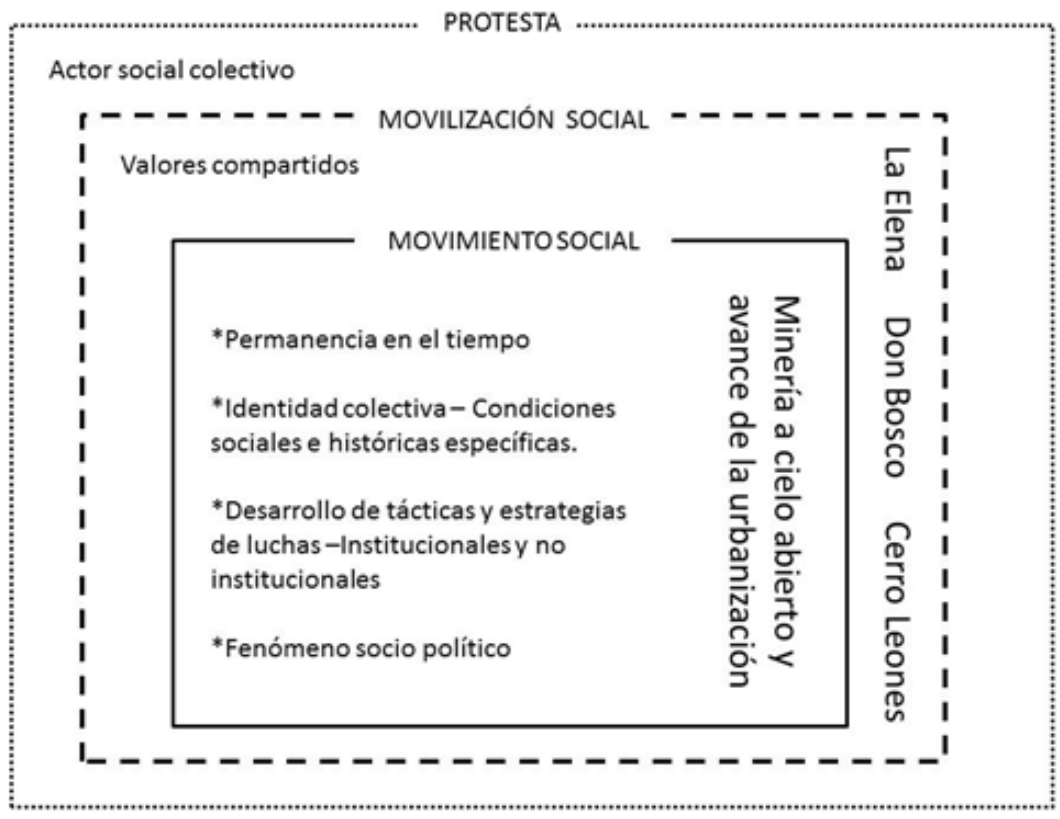

Fuente: Elaboración propia.

Figura 2. Acciones colectivas, movilizaciones, movimientos sociales y protestas en Tandil.

\section{CONCLUSIONES}

Este trabajo da cuenta de las diversas formas de organización social surgidas de problemáticas ambientales, a partir de la 
selección de cuatro casos que han ido ganando presencia a nivel local y regional. La selección de los casos permitió la sistematización de la información para su descripción y posterior comparación. El análisis se convierte, no obstante, en una base para futuros trabajos en igual sentido, que puedan contribuir al esclarecimiento de estos temas. Ello cobra importancia ante el hecho de que se trata de procesos de organización colectiva y disputas de intereses y valores que van ganando complejidad y merecen ser abordados con la rigurosidad ineludible ante la conflictividad social generada.

Como se ha consignado, la teoría existente sobre conflictos, acciones colectivas, protesta, movilizaciones y movimientos sociales nos permite captar la diversidad de estos procesos que tienen lugar en Tandil y que posiblemente contribuyan a configurar la realidad socioambiental de este territorio.

Ambos sucesos se enmarcan en la crisis de las instancias estatales como espacios de participación, que fluctúa entre la legitimación de otros espacios de construcción de poder societal y el intento de institucionalización con el que el Estado responde a la conflictividad socioambiental creciente. En este sentido, concordamos con Palacios cuando dice: "El descrédito de los políticos no debería hacernos olvidar que muchos cambios son más arduos de lograr sin una participación en política y de las políticas" (Palacios, 2006, p. 8). En consecuencia, en la investigación sobre estas problemáticas, el Estado se vuelve un actor central.

En relación a las características de los recursos implicados y los servicios ambientales en juego, se trata de dos recursos críticos para la vida local considerando que el agua subterránea es la principal fuente para consumo humano. A su vez las sierras, sus recursos minerales, biológicos (flora y fauna) y culturales asociados al paisaje han sido protagonistas de la historia urbana local. Han sido motores del desarrollo económico local a principios del siglo pasado y hoy constituyen un recurso turístico con valores paisajísticos y ambientales que se desean preservar.

En cuanto al rol de los diferentes actores implicados y del Estado en particular, en ambos casos aparecen con roles diferenciados el gobierno local y el provincial. El municipio, intentando conciliar los intereses particulares de los otros actores en conflicto, por momentos con actuaciones y discursos ambivalentes, dependiendo del contexto político local y provincial. La provincia, empleando políticamente las acciones desarrolladas en relación a la protección de las sierras.

En cuanto al estado de los conflictos en relación a la Ley de Paisaje Protegido, se logró expulsar a la actividad minera a cielo abierto del área de conservación creada. Se ha avanzado en la planificación y ordenación futura del área, aunque quedan sin resolver el proceso de avance de la urbanización sobre el espacio serrano protegido, las incompatibilidades entre el Plan de Ordenamiento Territorial vigente desde 2005 y la nueva ley de creación del área a proteger. 
Por último, se desea destacar que la necesaria y subsecuente profundización en cada uno de los casos aquí detallados deberá incluir en el análisis tanto los aspectos materiales vinculados a las prácticas de los actores envueltos en el accionar colectivo, como las luchas por los significados y sentidos que estos conflictos representan, ya que, como hemos comentado, implican disputas por sentidos culturales en relación a bienes naturales.

\section{REFERENCIAS}

- Acselrad, H. (Org.). (2004). Conflitos ambientais no Brasil. Rio de Janeiro: Relume Dumará-Fundação Heinrich Böll.

- Acselrad, H. (2010). Ambientalización de las luchas sociales - el caso del movimiento por justicia ambiental. Estudos Avançados, 24(68), 103-119.

- Bobbio, N., Matteucci, N. y Pasquino, G. (1991). Diccionario de política (6 $6^{\circ}$ ed.). México: Siglo XXI Editores.

- Escobar, A. (2011). El lugar de la naturaleza y la naturaleza del lugar: ¿globalización o postdesarrollo? En La colonialidad del saber: eurocentrismo y ciencias sociales (pp. 131- 161). $2^{\circ}$ Edición. Buenos Aires: CICCUS-CLACSO.

- Galafassi, G. y Zarrilli, A. G. (2002). Ambiente, sociedad y naturaleza. Entre la teoría social y la historia. Buenos Aires: Universidad Nacional de Quilmes.

- Girado, A. (2011). Conflicto socioambiental en la ciudad de Tandil: representaciones y prácticas en torno al recurso natural sierras. En V Congreso de la Asociación Argentina-Uruguaya de Economía Ecológica ASAUEE y $\vee$ Congreso Iberoamericano de sobre Desarrollo y Ambiente REVIBEC (CISDA). Santa Fe, Universidad del Litoral.

- Gohn, M. Da G. (2006). Teorias dos movimentos sociais: Paradigmas clássicos e contemporâneos ( $5^{\circ}$ ed.). São Paulo: Edições Loyola.

- Guerrero, E. M. (2011). Conflictos ambientales urbanos. Estrategias de movilización asociadas al acceso al agua potable en Tandil, Argentina. Revista Investigación y Desarrollo, 19(1), 196-211.

- Guerrero, E. M. (2012). Eventos hídricos excepcionales en la ciudad de Tandil, su espacialización histórica y su relación con la gestión del agua superficial. Revista Geousal, VI (13), 1-13.

- Guerrero, E. M. (2013). Caracterización de los movimientos urbanos ambientales vinculados a la gestión del agua. Estrategias sociales por el acceso al agua potable en Tandil, Argentina. Revista Iberoamericana de Economía Ecológica, 20, 17-26. Recuperado de http://www.redibec.org/IVO/rev20_02.pdf

- Hesse, A. (2012). Movimientos Socio-Ambientales de la provincia de Buenos Aires. Asamblea Ciudadana por la Preservación de las Sierras: características e impactos de su accionar. Tesis de Licenciatura en Diagnóstico y Gestión Ambiental. UNICEN.

- Ley de Paisaje Protegido No 14.126.

- Martínez Alier, J. (2004). El ecologismo de los pobres. Conflictos ambientales y lenguajes de valoración. Barcelona: Icaria AntrazytFLACSO. 
- Multisectorial por la Preservación de las Sierras de Tandil y Asamblea Ciudadana en Defensa de las Sierras. (2011). Libro verde. La lucha por la preservación de las Sierras de Tandil 19992011. Recuperado de http://www.sierrasprotegidas.com.arl

- Municipio de Tandil. Plan de Desarrollo Territorial (PDT) aprobado en 2005.

- Palacios, G. (2006). Breve guía de introducción a la Ecología Política (Ecopol): Orígenes, inspiradores, aportes y temas de actualidad. Gestión y Ambiente, 9(3), 7-20.

- Ramírez Sáiz, J. M. (1991). El movimiento urbano popular (MUP): teoría y método. En El estudio de los movimientos sociales: Teoría y Método (pp. 93-109). México: Coedición de El Colegio de Michoacán y Universidad Autónoma Metropolitana Unidad Xochimilco (UAM-X).

- Riechmann, J. y Fernández Buey, F. (1994). Redes que dan libertad: Introducción a los nuevos movimientos sociales. España: Paidós.

- Rodríguez, C. I. (2010). Evaluación ambiental de las condiciones de explotación y uso del recurso hídrico subterráneo en el barrio Cerro Los Leones, Tandil. Tesis de Maestría en Evaluación Ambiental de Sistemas Hidrológicos (Mención Ecohidrología). Universidad Nacional de La Plata.

- Rodríguez, C. I., Jacinto, G. P., Ruiz de Galarreta, V. A. y Banda Noriega, R. B. (2010). Gestión del agua subterránea en el Barrio Cerro Los Leones, Tandil (Argentina). Revista Ciencia Docencia y Tecnología, 41, 193-216.

- Rodríguez, C. I., Miranda del Fresno, M. C., Miguel, R. E., Ulberich, A. C. y Ruiz de Galarreta, A. (2013). Cambios de uso del suelo e impactos sobre el agua subterránea en un barrio al sur de Tandil, Buenos Aires, Argentina. Revista AUGM Domus, 5, 75-90.

- Saldi, L. (2011). Procesos identitarios, naturaleza y políticas estatales en el Noreste de Mendoza (Argentina). Tesis doctoral en Ciencias Sociales con mención en Sociología. Facultad de Ciencias Políticas y Sociales, Universidad Nacional de Cuyo.

- Sartori, G. y Morlino, L. (Eds.). (1994). La comparación en las ciencias sociales. Madrid: Editorial Alianza.

- Schuster, F. (2005). Izquierda política y movimientos sociales en Argentina contemporánea. En Rodríguez Garavito, C. A., Barrett, P. S. y Chávez, D. (Eds.). La nueva izquierda en América Latina: sus orígenes y trayectoria futura. Buenos Aires: Grupo Editorial Norma.

- Scribano, A. (2005). Itinerarios de la protesta y del conflicto social. Argentina: Centro de Estudios Avanzados.

- Ulberich, A., Miranda del Fresno, M. C. y Morrone, M. (2012). Avance de la edificación en el sector serrano S-SE de la ciudad de Tandil, Argentina. En Estudios Ambientales III-Área de Tandilia (pp. 131-138). Tandil: CINEA.

- Wagner, L. S. (2011). Problemas Ambientales y Conflicto Social en Argentina: Movimientos socioambientales en Mendoza. La defensa del agua y el rechazo a la megaminería en los inicios del Siglo XXI. Tesis Doctoral Mención Ciencias Sociales y Humanas. Universidad Nacional de Quilmes. Recuperado de www.eumed.net/tesis/2011/lsw/ 
1. Msc. en Economía Ecológica y Gestión Ambiental. Centro de Investigaciones y Estudios Ambientales CINEA, FCH, UNICEN, Argentina. emarguerr@gmail.com

2. Dra. en Ciencias Sociales y Humanas. Grupo de Historia Ambiental y Antropología. Instituto Argentino de Nivología, Glaciares y Ciencias Ambientales (IANIGLA) - Centro Científico Tecnológico (CCT) - Consejo Nacional de Investigaciones Científicas y Técnicas (CONICET). lucreciawagner@yahoo.com.ar

3. Lic. en Diagnóstico y Gestión Ambiental. Mag. en Evaluación Ambiental de Sistemas Hidrológicos (Mención Ecohidrología). Centro de Investigaciones y Estudios Ambientales CINEA, FCH, UNICEN, Argentina. corinairis@yahoo.com

4. Msc. en Gestión y Auditoría Ambiental. Centro de Investigaciones y Estudios Ambientales CINEA, FCH, UNICEN, Argentina. Becaria - Consejo Nacional de Investigaciones Científicas y Técnicas (CONICET). beatrizsosa33@gmail.com

5. Martínez Alier menciona al ecologismo popular o ecologismo de los pobres como la "tercera corriente" porque también identifica otras dos: la del culto a lo silvestre y la de la ecoeficiencia. Para mayor información ver: Martínez (2004).

6. Para un abordaje más profundo respecto a las corrientes teóricas sobre movimientos sociales y acción colectiva, y las características de cada una de estas nociones, se recomienda la lectura de Gohn (2006).

7. El Plan de Ordenamiento Territorial, puso límites al tamaño de los lotes en determinados sectores de desarrollo urbano reciente, esto es visto como un problema frente a la especulación inmobiliaria de predios remanentes de actividades rurales y periurbanas (quintas, establecimientos rurales, etc.).

Para citar este artículo: Guerrero, E. M., Wagner, L. S., Rodríguez, C. I. y Sosa, B. S. (2015). Acciones colectivas y recursos naturales en conflicto. Historia ambiental de luchas urbanas por agua y sierras en Tandil, Argentina. Revista Luna Azul, 41, 274-295. Recuperado de http://lunazul.ucaldas.edu.co/index.php?option=content\&t ask=view\&id=1066 